\title{
Effects of Thyroid Status and Thyrostatic Drugs on Hepatic Glucuronidation of lodothyronines and Other Substrates in Rats
}

\author{
Induction of Phenol UDP-Glucuronyltransferase by Methimazole
}

Theo J. Visser, ${ }^{1}$ Ellen Kaptein, ${ }^{1}$ Anthonie Gijzel, ${ }^{1}$ Wouter W. de Herder, ${ }^{1}$

Mark L. Cannon, ${ }^{1}$ Fred Bonthuis, ${ }^{2}$ and Wim J. de Greef ${ }^{3}$

Department of Internal Medicine III, 'Department of Internal Medicine I, and ${ }^{3}$ Department of Endocrinology and Reproduction, Erasmus University Medical School, Rotterdam. The Netherlands

Glucuronidation of iodothyronines in rat liver is catalyzed by at least three UDP-glucuronyltransferases (UGTs): bilirubin UGT, phenol UGT, and androsterone UGT. Bilirubin and phenol UGT activities are regulated by thyroid hormone, but the effect of thyroid status on hepatic glucuronidation of iodothyronines is unknown. We examined the effects of hypothyroidism induced by treatment of rats with propylthiouracil (PTU) or methimazole (MMI) or by thyroidectomy as well as the effects of T4-induced hyperthyroidism on the hepatic UGT activities for T4, T3, bilirubin, $p$-nitrophenol (PNP), and androsterone. Bilirubin UGT activity was increased in MMI- or PTU-induced hypothyroid and thyroidectomized rats, and decreased in hyperthyroid animals. T4 and, to a lesser extent, T3 UGT activities were increased in MMI- or PTU-induced hypothyroid rats, and $\mathrm{T} 4$ but not $\mathrm{T} 3$ glucuronidation also showed a significant increase in thyroidectomized rats. T4 but not T3 UGT activity was slightly decreased in hyperthyroid rats. While PNP UGT activity was decreased in thyroidectomized rats and increased in hyperthyroid animals, it was also markedly increased by MMI and slightly increased by PTU-induced hypothyroidism. In T4-substituted rats, MMI did not affect $T 4, T 3$, bilirubin and androsterone UGT activities but again strongly induced PNP UGT activity, indicating that this represented a direct induction of PNP UGT by the drug independent of its thyrostatic action. Androsterone UGT activity was hardly affected by thyroid status. Our results suggest a modest, negative control of the hepatic glucuronidation of thyroid hormone by

Received August 16, 1995; Revised October 31, 1995; Accepted November 22,1995 .

Author to whom all correspondence and reprint requests should be addressed: Dr. Theo J. Visser, Department of Internal Medicine III, Erasmus University Medical School, PO Box 1738. Room Bd 234, 3000 DR Rotterdam, The Netherlands. thyroid status, which may be mediated by changes in bilirubin UGT activity. To our knowledge, this is the first report of the marked induction of a hepatic enzyme by $\mathrm{MMI}$, which is not mediated by its thyroid hormonelowering effect.

Key Words: Thyroid hormone; hypothyroidism; hyperthyroidism; propylthiouracil; methimazole; thyroidectomy; liver; UDP-glucuronyltransferases; type I iodothyronine deiodinase; thyroxine; 3,3',5-triiodothyronine; 3, 3',5'-triiodothyronine; bilirubin; phenol; androsterone.

\section{Introduction}

Deiodination is the primary pathway of thyroid hormone metabolism, since it is involved with the regulation of hormonal activity (Köhrle et al. 1991; St. Germain, 1994). The prohormone $\mathrm{T} 4$ is converted by outer ring deiodination (ORD) to bioactive $\mathrm{T} 3$ and by inner ring deiodination (IRD) to inactive rT3. IRD is also a major step in the inactivation of T3, yielding the same metabolite (3,3'-diiodothyronine) as that generated by ORD of rT3 (Köhrle et al. 1991; St. Germain, 1994).

Conjugation of the phenolic hydroxyl group with sulfate or glucuronic acid represents other important metabolic pathways for thyroid hormone (Visser, 1990, 1994; Curran and DeGroot, 1991). In general, conjugation is a detoxification reaction that increases the water-solubility of endogenous and foreign compounds, thus facilitating their excretion in bile and/or urine. However, sulfation of iodothyronines is an exceptional case, since it strongly accelerates the deiodination of these compounds by the type I iodothyronine deiodinase (ID-I). Therefore, under normal conditions, very little thyroid hormone sulfates are detected in blood, bile, or urine, but they accumulate to high 
levels in situations where ID-I activity is inhibited (Visser, 1990, 1994; Curran and DeGroot, 1991).

Thyroid hormone is glucuronidated by UDP-glucuronyltransferases (UGTs) located in the endoplasmic reticulum of liver and other tissues (Visser, 1990, 1994; Curran and DeGroot, 1991). Iodothyronine glucuronides are excreted in bile, but this is not an irreversible route for thyroid hormone disposal. The glucuronides are extensively deconjugated in the intestinal lumen, in particular by $\beta$-glucuronidases of bacterial origin, and part of the liberated iodothyronines is reabsorbed (Hazenberg et al., 1988; De Herder et al., 1989; Rutgers et al., 1989). Because of this enterohepatic circulation, the intestinal content represents a large pool of thyroid hormone (Nguyen et al., 1993).

Previous studies in our laboratory have suggested that at least three UGT isoenzymes are involved with the glucuronidation of iodothyronines in rats (Beetstra et al., 1991; Visser et al., 1991a, 1993a, 1993b, 1993c; Van Raaij et al., 1993). Especially T4 and rT3 are glucuronidated by one of the bilirubin UGTs as well as by one of the phenol UGTs. However, T3 is predominantly glucuronidated by androsterone UGT (Visser et al., 1993b). Despite the quantitative importance of the glucuronidation of thyroid hormone, at least in rats, little is known about its regulation. In this study, we addressed the question of whether the glucuronidation of thyroid hormone in rats is regulated by thyroid status. For this, we investigated the effects of hypothyroidism induced by the goitrogens 6-propyl-2thiouracil (PTU) or methimazole (MMI) and those of hyperthyroidism induced by $\mathrm{T} 4$ treatment on the liver microsomal UGT activities for T4, T3, bilirubin, $p$-nitrophenol (PNP), and androsterone. The efficacy of these treatments was checked by analysis of serum T4, T3, and TSH levels as well as hepatic ID-I activity, which is positively regulated by thyroid status (Köhrle et al., 1991; St. Germain, 1994). Among other things, the results demonstrate a potent induction of PNP UGT activity by MMI, which is not mediated by its thyroid hormone-lowering action.

\section{Results}

Table 1 shows the effects of treatment of rats for $2 \mathrm{wk}$ with PTU or MMI on serum T4 and T3 levels as well as on hepatic ID-I activity. Both goitrogens produced an $80 \%$ decrease in serum $\mathrm{T} 4$ and a $60 \%$ decrease in serum $\mathrm{T} 3$. The hypothyroid status of the liver in MMI-treated rats was substantiated by the $70 \%$ decrease in ID-I activity. The greater decrease in ID-I activity induced by PTU is explained by the direct inhibition of ID-I by this drug.

Figure 1 shows the effects of PTU or MMI treatment on hepatic UGT activities for different substrates. Both PTU and MMI induced significant increases in T4 and T3 UGT activities, the effects being greater with $\mathrm{T} 4$ than with $\mathrm{T} 3$ as substrate. Whereas PTU treatment resulted in a small increase in PNP UGT activity, a 130\% increase in PNP
Table 1

Effects of Treatment of Rats with PTU or MMI on Serum T4 and T3 Levels and Hepatic ID-I Activity ${ }^{a}$

\begin{tabular}{lccc}
\hline & \multicolumn{3}{c}{ Group } \\
\cline { 2 - 4 } Parameter & Control & PTU & MMI \\
\hline T4, nmol/L & $61 \pm 5$ & $13 \pm 2^{b}$ & $13 \pm 2^{b}$ \\
T3, nmol/L & $1.31 \pm 0.11$ & $0.51 \pm 0.10^{h}$ & $0.47 \pm 0.11^{b}$ \\
ID-I, $\mathrm{pmol} / \mathrm{min} / \mathrm{mg}$ & $462 \pm 51$ & $47 \pm 11^{b}$ & $153 \pm 97^{b}$ \\
\hline
\end{tabular}

${ }^{a}$ Rat treatment was for 2 wk with $0.1 \%$ (wt/vol) PTU or MMI in the drinking water. Results are presented as mean $\pm \mathrm{SD}$ of eight rats in each group.

${ }^{b} p<0.001$ vs control.

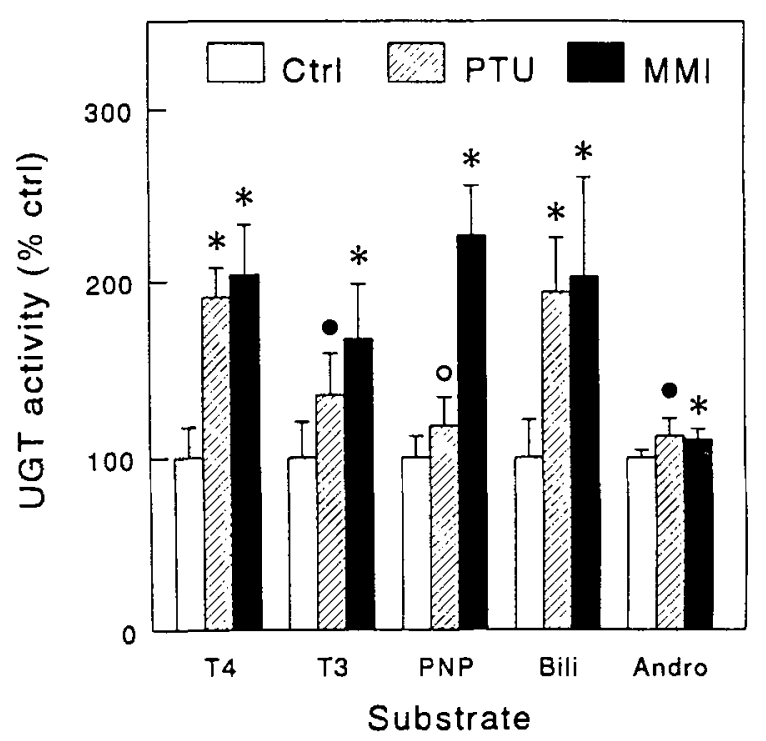

Fig. 1. Effects of treatment of rats for 2 wk with $0.1 \%$ (wt/vol) PTU or MMI in the drinking water on hepatic UGT activities. Results are expressed as percentage of the mean control value (T4 $1.05 \mathrm{pmol}, \mathrm{T} 30.75 \mathrm{pmol}$, PNP $51 \mathrm{nmol}$, bilirubin $0.62 \mathrm{nmol}$, and androsterone $2.68 \mathrm{nmol}$ per min and per $\mathrm{mg}$ protein), and presented as mean $\pm \mathrm{SD}$ of eight rats per group. $\bigcirc, p<0.025$ vs control;,$p<0.01$ vs control; ${ }^{*}, p<0.001$ vs control.

UGT activity was observed in MMI-treated rats. Both PTU and MMI induced $a \approx 100 \%$ increase in bilirubin UGT activity and a slight but significant increase in androsterone UGT activity.

Table 2 shows that serum T4 and T3 levels in rats treated with substitution doses of T4 in combination with MMI did not differ from those in rats treated with T4 alone. Table 2 also demonstrates that hepatic deiodinase activity was not affected by MMI in "T4-substituted" rats.

Figure 2 shows the effects of treatment of T4-substituted rats with MMI on hepatic UGT activities. The results clearly show that T4 and T3 UGT activities were not affected by MMI if its thyroid hormone-lowering effect was prevented by $\mathrm{T} 4$ treatment. In addition, neither androsterone nor bilirubin UGT activity was influenced when MMI was 
Table 2

Effects of Treatment of Rats with MMI and T4 vs T4 Alone on Serum T4 and T3 Levels and Hepatic ID-I Activity ${ }^{a}$

\begin{tabular}{lcr}
\hline & \multicolumn{2}{c}{ Treatment } \\
\cline { 2 - 3 } Parameter & $\mathrm{T} 4$ & $\mathrm{~T} 4+\mathrm{MMI}$ \\
\hline $\mathrm{T} 4 . \mathrm{nmol} / \mathrm{L}$ & $156.3 \pm 56.8$ & $132.5 \pm 22.5$ \\
$\mathrm{~T} 3, \mathrm{nmol} / \mathrm{L}$ & $1.19 \pm 0.20$ & $1.27 \pm 0.34$ \\
$\mathrm{ID}-\mathrm{I}, \mathrm{pmol} / \mathrm{min} / \mathrm{mg}$ & $883 \pm 71$ & $899 \pm 130$ \\
\hline
\end{tabular}

"Rats were treated for 2 wk with daily ip injections of $1 \mu \mathrm{g} \mathrm{T} 4 /$ $100 \mathrm{~g}$ body $\mathrm{wt}$ and $0.1 \%(\mathrm{wt} / \mathrm{vol}) \mathrm{MMI}$ in the drinking water or with $\mathrm{T} 4$ alone. Results are presented as mean $\pm \mathrm{SD}$ of eight rats in each group.

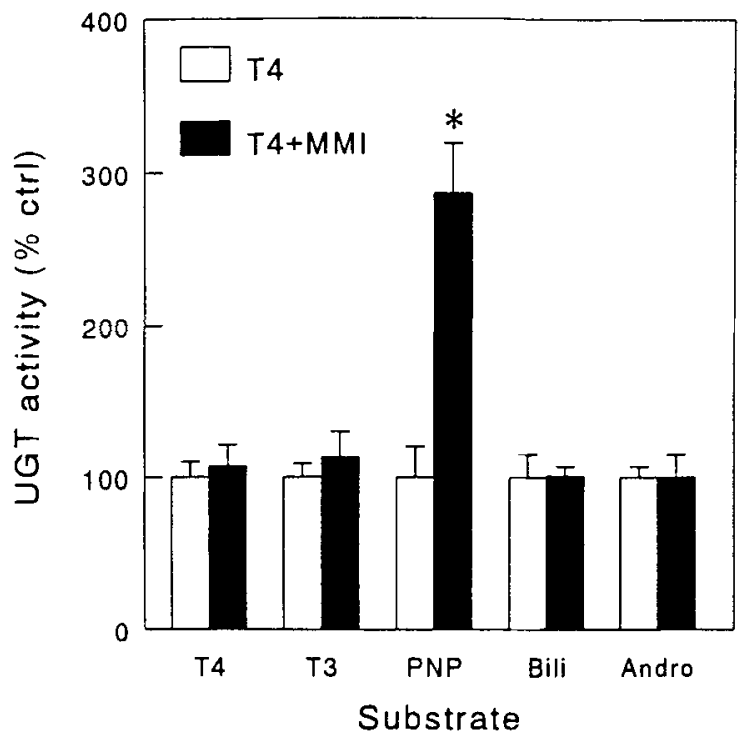

Fig. 2. Effects of truatment of rats for $2 \mathrm{wk}$ with daily injections of $1 \mu \mathrm{g} \mathrm{T} 4 / 100 \mathrm{~g}$ body wt and $0.1 \%$ (wt/vol) MMI in the drinking water or with $\mathrm{T} 4$ alone (control) on hepatic UGT activities. Results are expressed as percentage of the mean control value (T4 1.94 pmol, T3 $1.36 \mathrm{pmol}$, PNP $49 \mathrm{nmol}$, bilirubin $0.96 \mathrm{nmol}$, and androsterone $6.88 \mathrm{nmol}$ per min and per mg protein), and presented as mean $\pm \mathrm{SD}$ of eight rats per group. ${ }^{*}, p<0.001$ vs control.

administered in combination with T4. However, PNP UGT activity was almost threefold higher in rats treated with MMI and T4 than in rats receiving only $\mathrm{T} 4$.

Table 3 shows the serum hormone levels and hepatic ID-I activity in thyroidectomized rats and euthyroid controls. Serum T4 was decreased by about $80 \%$ and serum T3 by about $50 \%$, whereas serum TSH was increased $\approx 13$-fold after thyroidectomy. The hypothyroid status of the livers of the thyroidectomized animals is indicated by the $\approx 50 \%$ decrease in ID-I activity.

Figure 3 shows the effects of thyroidectomy on hepatic UGT activities. T4 UGT activity was significantly higher in thyroidectomized than in control rats, but T3 UGT activity was not affected by thyroidectomy. PNP UGT activity was significantly decreased and bilirubin UGT activity was
Table 3

Effects of Thyroidectomy on Serum T4, T3 and TSH Levels and Hepatic ID-I Activity"

\begin{tabular}{lcc}
\hline & \multicolumn{2}{c}{ Group } \\
\cline { 2 - 3 } Parameter & Control & Thyroidectomized \\
\hline T4, nmol/L & $42.0 \pm 10.4$ & $8.8 \pm 4.7^{b}$ \\
T3, nmol $/ \mathrm{L}$ & $0.86 \pm 0.32$ & $0.45 \pm 0.14^{c}$ \\
TSH $(\mathrm{ng} / \mathrm{ml})$ & $0.82 \pm 0.57$ & $10.46 \pm 3.92^{h}$ \\
ID-I, $\mathrm{pmol} / \mathrm{min} / \mathrm{mg}$ & $1125 \pm 261$ & $559 \pm 164^{h}$ \\
\hline
\end{tabular}

${ }^{a}$ Results are presented as mean ${ }^{ \pm} \mathrm{SD}$ of four control and eight thyroidectomized rats.

${ }^{h} p<0.001$ vs control.

c $p<0.01$ vs control.

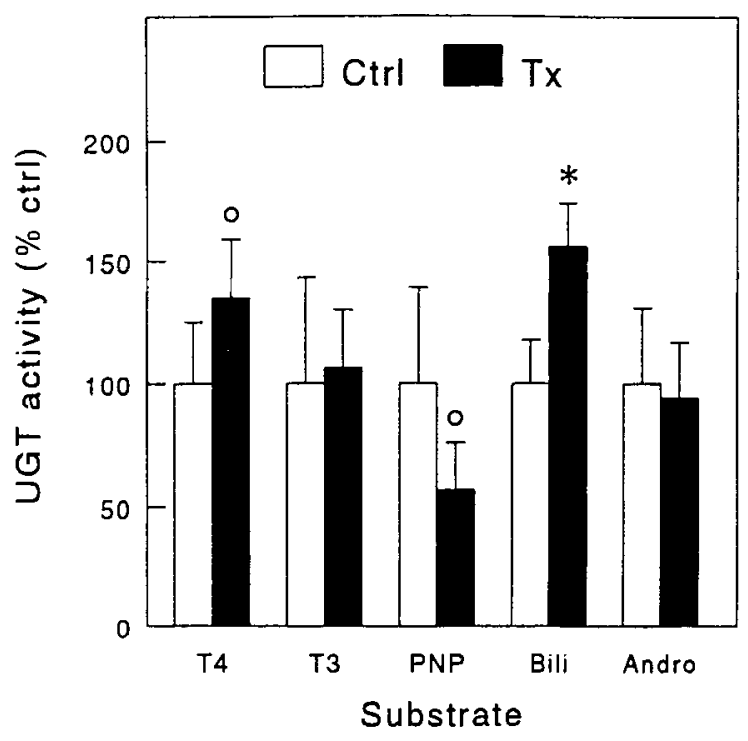

Fig. 3. Effects of thyroidectomy on hepatic UGT activities. Results are expressed as percentage of the mean control value (T4 $2.32 \mathrm{pmol}, \mathrm{T} 31.91 \mathrm{pmol}$, PNP $49 \mathrm{nmol}$, bilirubin $0.62 \mathrm{nmol}$, and androsterone $3.87 \mathrm{nmol}$ per min and per mg protein), and presented as mean \pm SD of four control and eight thyroidectomized rats. $\bigcirc, p<0.05$ vs control; ${ }^{*}, p<0.001$ vs control.

significantly increased after thyroidectomy. Androsterone UGT activity was not affected in the thyroidectomized animals.

Table 4 shows the effects of treatment of rats for $1 \mathrm{wk}$ with daily injections of $10 \mu \mathrm{g} \mathrm{T} 4 / 100 \mathrm{~g}$ body wt on serum $\mathrm{T} 4$ and T3 levels and on hepatic ID-I activity. All these parameters were $>2$-fold higher in the hyperthyroid animals than in the euthyroid controls.

Figure 4 presents the effects of hyperthyroidism on hepatic UGT activities for different substrates. T4 but not T3 UGT activity was slightly decreased in the hyperthyroid rats. PNP activity was $\approx 80 \%$ increased and bilirubin UGT activity $\approx 50 \%$ decreased in hyperthyroid vs euthyroid rats. Androsterone UGT activity was not significantly affected by induction of hyperthyroidism. 
Table 4

Effects of Treatment of Rats with Excess T4 on Serum T4 and T3 Levels and Hepatic ID-I Activity ${ }^{a}$

\begin{tabular}{lll}
\hline & \multicolumn{2}{c}{ Treatment } \\
\cline { 2 - 3 } Parameter & \multicolumn{1}{c}{ Control } & \multicolumn{1}{c}{$\mathrm{T} 4$} \\
\hline $\mathrm{T} 4, \mathrm{nmol} / \mathrm{L}$ & $57 \pm 10$ & $125 \pm 9^{b}$ \\
$\mathrm{~T} 3, \mathrm{nmol} / \mathrm{L}$ & $1.62 \pm 0.15$ & $3.37 \pm 0.81^{b}$ \\
$\mathrm{ID}-\mathrm{I}, \mathrm{pmol} / \mathrm{min} / \mathrm{mg}$ & $419 \pm 85$ & $1048 \pm 191^{b}$ \\
\hline
\end{tabular}

${ }^{a}$ Rats were treated for $1 \mathrm{wk}$ with daily ip injections of $10 \mu \mathrm{g}$ $\mathrm{T} 4 / 100 \mathrm{~g}$ body wt or vehicle. Results are presented as mean $\pm \mathrm{SD}$ of eight rats in both groups.

${ }^{b} p<0.001$ vs control.

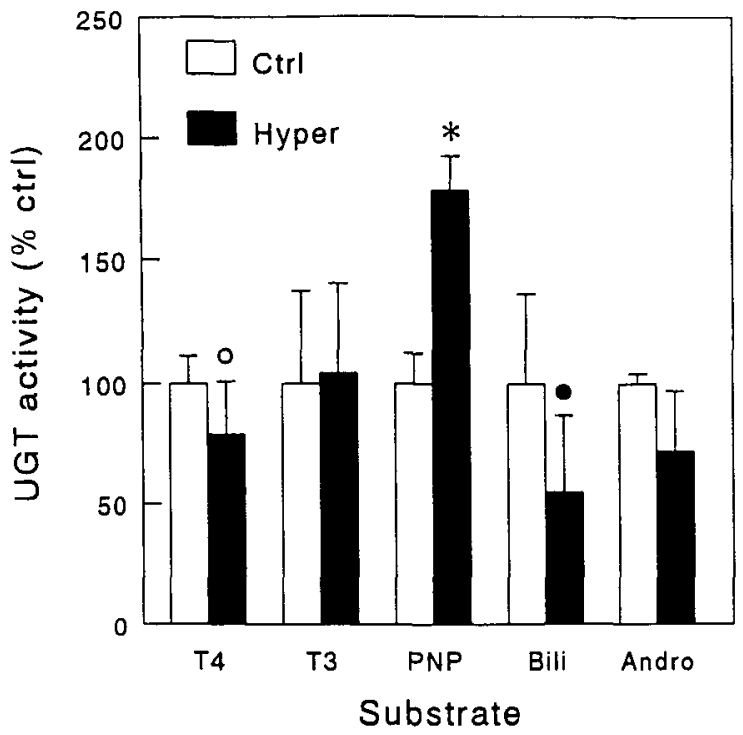

Fig. 4. Effects of T4-induced hyperthyroidism on hepatic UGT activities. Results are expressed as percentage of the mean control value (T4 1.14 pmol, T3 0.98 pmol, PNP $63 \mathrm{nmol}$, bilirubin 0.53 nmol, and androsterone $3.57 \mathrm{nmol}$ per min and per mg protein), and expressed as mean $\pm \mathrm{SD}$ of eight rats per groups. For $\mathrm{T} 3$ and androsterone UGT activities: $n=7$ (one LA rat in each group). $O$, $p<0.05$ vs control;,$p<0.025$ vs control; $*, p<0.001$ vs control.

\section{Discussion}

Previous work in our laboratory has suggested that at least three UGT isoenzymes are involved with the glucuronidation of T4 and T3 in rat liver (Beetstra et al., 1991; Visser et al., 1991a, 1993a, 1993b; Van Raaij et al., 1993). This was based on the following findings:

1. Parallel with an increase in PNP UGT activity, hepatic T4 but not T3 UGT activity is strongly induced by treatment of rats with 3-methylcholanthrene (MC)-type inducers;

2. Parallel with an increase in bilirubin UGT activity, hepatic T4 but not T3 UGT activity is strongly induced by treatment of rats with clofibrate or ciprofibrate;

3. Hepatic T4 but not T3 UGT activity is strongly decreased in Gunn rats, which have a defect in the UGTl gene coding for multiple bilirubin and phenol UGTs (Emi et al., 1995);
4. Relative to normal Wistar HA (high activity) rats, $\mathrm{T} 3$ but not T4 UGT activity is strongly decreased in Wistar LA (low activity), Fischer, and WAG rats, which have a defect in the gene coding for androsterone UGT (Homma et al., 1992).

These results, thus, suggest that T4 is predominantly glucuronidated in rat liver by both bilirubin UGT and phenol UGT, whereas $\mathrm{T} 3$ is primarily conjugated by androsterone UGT. This is supported by studies with V79 cell lines transfected with cDNA of different human UGT isoenzymes, showing significant glucuronidation of $\mathrm{T} 4$ (and rT3) by the bilirubin UGT HP3, as well as the phenol UGT HP4 (Visser et al., 1993c). However, in contrast to the latter "bulky" phenol-preferring isoenzyme, little or no glucuronidation of iodothyronines was observed with the planar phenol-preferring isoenzyme HP1, which glucuronidates substrates such as 1-naphthol and PNP. Therefore, the parallel increase in iodothyronine and PNP UGT activities in response to MC-type inducers does not-as we initially suggested (Beetstra et al., 1991) — reflect the induction of a common enzyme but rather the simultaneous induction of different isoenzymes, i.e., one for PNP (HP I-like) and one for iodothyronines (HP4-like) (Visser et al., 1993b).

Drugs and xenobiotics that accelerate the metabolic clearance of T 4 by induction of UGT isoenzymes include polychlorobiphenyls, dioxin, fibrates, phenobarbital, and other anticolvulsant drugs (McClain et al, 1989; Beetstra et al., 1991; Visser et al., 1991a, 1993b; Saito et al.. 1991; De Sandro et al., 1991, 1992; Barter and Klaassen, 1992a, 1992b; Van Raaij et al., 1993). The resultant decrease in serum T4 causes an increase in TSH secretion and, thus, a stimulation of thyroid activity. Chronic treatment with such compounds may even be associated with development of thyroid tumors in rats (McClain, 1989) and of goiter in humans (Hegedüs et al., 1985; Davies and Franklin, 1991). Although glucuronidation is also under normal conditions a major pathway of thyroid hormone metabolism in rats and perhaps also in humans, little is known about its regulation. It has previously been reported that bilirubin UGT activity is increased while PNP UGT activity is decreased in thyroidectomized rats (Roy Chowdhury et al., 1983; Van Steenbergen et al., 1989). Conversely, bilirubin UGT activity is decreased while PNP UGT activity is increased in hyperthyroid rats (Roy Chowdhury et al., 1983; Van Steenbergen et al., 1989). Therefore, we investigated the possible effects of thyroid status on hepatic UGT activities for the iodothyronines T4 and T3 in comparison with the UGT activities for the "standard" substrates bilirubin, PNP, and androsterone.

Initially, the effects of hypothyroidism were investigated in rats that had been made hypothyroid by treatment with PTU or MMI. In agreement with the aforementioned published reports (Roy Chowdhury et al., 1983; Van Steenbergen et al., 1989), we found that hepatic bilirubin UGT activity was significantly increased in MMI- or PTUinduced hypothyroid rats. In contrast to the previously reported decrease in PNP UGT activity in thyroidectomized 
rats (Roy Chowdhury et al., 1983; Van Steenbergen et al., 1989), we noticed a slight increase in PNP UGT activity in PTU-treated rats and a marked enzyme induction in MMI-treated rats. This suggested a direct induction of PNP UGT by MMI and to some extent also by PTU, not mediated by their thyrostatic action. This possibility was tested by administration of MMI to rats in which the induction of hypothyroidism was prevented by replacement doses of $\mathrm{T} 4$. In this setting, MMI did not affect the thyroid status of the animals, since not only serum $\mathrm{T} 4$ and $\mathrm{T} 3$ levels but also hepatic ID-I activity was identical in rats treated with MMI and T4 and in those treated with T4 alone. Bilirubin UGT activity was not affected by administration of MMI to T4-substituted rats, but PNP UGT was markedly induced by the thyrostatic drug. This supports the direct induction of PNP UGT in rat liver by MMI.

Our results in thyroidectomized rats are in agreement with the aforementioned reports (Roy Chowdhury et al., 1983; Van Steenbergen et al., 1989), since we observed an increase in bilirubin UGT activity and a decrease in PNP UGT activity compared with euthyroid controls. Also in agreement with the literature, we found a decreased bilirubin UGT activity and an increased PNP UGT activity in hyperthyroid animals. At least two bilirubin UGTs and at least two phenol UGTs are encoded by the UGTI gene, a gene complex comprising multiple unique exons (exons I) and a set of four common exons (exons II-V) (Emi et al., 1995). Transcription may start at any of the different unique exons, each under control of its own promoters, yielding primary transcripts of varying length depending on the location of the relevant exon I in the UGTI gene. By differential splicing of these primary transcripts, multiple mRNA species are produced that each combine a unique exon I, coding for the substrate-binding domain, with the common exons II-V, coding for the cofactor-binding domain of the enzyme (Owens and Ritter, 1992; Burchell et al., 1994; Emi et al., 1995). An attractive explanation of the effects of thyroid status on bilirubin and PNP UGT activities is that the promoter of one or more bilirubin UGT-specific exons I is under negative control of the T3 receptor, whereas the promoter of one or more phenol UGT-specific exons I is under positive control of the $\mathrm{T} 3$ receptor. Further studies are required to test this hypothesis. It also remains to be determined if it is the same phenol UGT isoenzyme(s) that is (are) regulated by thyroid hormone as well as induced by MMI.

Except for two preliminary communications in abstract form (Visser et al., 1991b; Van der Heide et al., 1992), the effects of thyroid status on hepatic iodothyronine UGT activity have not been reported before. Our results demonstrate that T4 UGT activity is significantly increased in hypothyroid rats and marginally decreased in hyperthyroid animals. It is tempting to explain these effects by the parallel variations in bilirubin UGT activity, for which T4 is known to be a substrate (Visser et al., 1993c). Both T3 and androsterone UGT activities were significantly increased by MMI or PTU treatment but unaffected by thyroidectomy. These different responses may be explained by the more severe hypothyroidism induced by the drugs than by thyroidectomy, which is supported by the larger decrease in hepatic ID-I activity in MMI-treated than in thyroidectomized rats. The larger increase in $\mathrm{T} 3$ than in androsterone UGT activity in drug-induced hypothyroidism suggests that $\mathrm{T} 3$ is also glucuronidated to some extent by bilirubin UGT.

The relevance of the observed changes in iodothyronine UGT activities for the thyroid status-dependent regulation of thyroid hormone metabolism remains to be determined. It should be realized that in vivo changes in cofactor (UDPGA) concentrations may be as important as changes in UGT activity in determining overall hepatic glucuronidation (Qu et al., 1995), and the effects of thyroid status on hepatic UDPGA levels are unknown. The opposite changes in ID-I and T4 UGT activities suggest that hepatic T4 metabolism shifts from deiodination to glucuronidation in hypothyroid rats and vice versa in hyperthyroid animals. The importance of glucuronidation for thyroid hormone metabolism in humans has not been established. Glucuronidation of $\mathrm{T} 4$ has been demonstrated with human liver microsomes and human bilirubin and phenol UGTs (Visser et al., 1993c). These enzymes are encoded by a similar UGTI gene complex as in rats (Owens and Ritter, 1992; Burchell et al., 1994; Emi et al., 1995), but it is unknown if their expression is also regulated by thyroid hormone.

In conclusion, we have demonstrated that iodothyronine UGT activity in rat liver is markedly increased in hypothyroidism and slightly decreased in hyperthyroidism, probably reflecting the parallel changes in bilirubin UGT activity. PNP UGT activity is strongly induced by MMI treatment, which is independent of the thyrostatic potency of this drug.

\section{Materials and Methods}

\section{Materials}

$\left[3^{\prime}, 5^{\prime}-{ }^{-125} \mathrm{I}\right] \mathrm{T} 4,\left[3^{\prime}-{ }^{125} \mathrm{I}\right] \mathrm{T} 3$, and $\left[3^{\prime}, 5^{\prime}--^{125} \mathrm{I}\right] \mathrm{rT} 3$ were obtained from Amersham (Amersham, England); T4, T3, PTU, MMI, dithiothreitol (DTT), bilirubin, and BSA from Sigma (St. Louis, MO); rT3 from Henning (Berlin, Germany); $\left[{ }^{3} \mathrm{H}\right]$ androsterone from NEN (Boston, MA); androsterone from Steraloids (Wilton, NH); PNP from Merck (Darmstadt, Germany); Brij 56 and Brij 58 from Serva (Heidelberg, Germany); UDP-glucuronic acid (UDPGA) from Boehringer Mannheim (Almere, The Netherlands); BCA protein assay reagent from Pierce (Oud Beijerland, The Netherlands); and Sephadex LH-20 from Pharmacia (Woerden, The Netherlands).

The purity of [ $\left.{ }^{125} \mathrm{I}\right] \mathrm{T} 3$ was checked by chromatography on Sephadex LH-20, showing that it could be used without further purification. $\left[{ }^{125} \mathrm{I}\right] \mathrm{T} 4$ and $\left[{ }^{125} \mathrm{I}\right] \mathrm{rT} 3$ were purified on Sephadex LH-20 immediately before each assay (Visser et al., 1993b) 


\section{Rat Treatments}

All experiments were done with groups of eight male Wistar rats (weighing 200-350 g) obtained from Harlan Sprague-Dawley (Zeist. The Netherlands) or bred locally. They were housed in a controlled animal room with a $14-\mathrm{h}$ light: 10-h dark photocycle, and they were provided ad libitum with food and drinking water. Rats were made hypothyroid by treatment for 2 wk with drinking water containing $0.1 \%$ (wt/vol) PTU or MMI. Euthyroid controls received plain drinking water. To check for nonthyrostatic effects of MMI, rats were treated for 2 wk with $0.1 \% \mathrm{MMI}$ in the drinking water and daily ip injections with $1 \mu \mathrm{g} \mathrm{T} 4 / 100 \mathrm{~g}$ body wt, whereas controls received the same $\mathrm{T} 4$ injections but no MMI. Rats were also made hypothyroid by surgical thyroidectomy under ether anesthesia followed after $1 \mathrm{wk}$ by administration of $0.75 \mathrm{mCi}^{131} \mathrm{I}^{--}$; they were sacrificed two weeks later. Hyperthroidism was induced by treating rats for $7 \mathrm{~d}$ with daily ip injections of $10 \mu \mathrm{g} \mathrm{T} 4 / 100 \mathrm{~g}$ body wt, whereas control rats received injections with vehicle. At the end of the treatments ( $24 \mathrm{~h}$ after the last T4 dose), rats were anesthetized with ether and decapitated. Trunk blood was collected and serum was isolated and stored at $20^{\circ} \mathrm{C}$ until analysis of hormone levels. Livers were isolated, immediately frozen in liquid nitrogen, and stored at $80^{\circ} \mathrm{C}$ until further processing. All procedures were approved by the A nimal Welfare Committee (DEC) of the Erasmus University.

\section{Liver Enzyme Assays}

Liver microsomes were prepared as previously described (Visser et al., 1993b), suspended in $0.1 \mathrm{M}$ phosphate ( $\mathrm{pH} 7.2$ ), $2 \mathrm{~m} M$ EDTA and $1 \mathrm{~m} M$ DTT, at a protein concentration of $10-20 \mathrm{mg} / \mathrm{mL}$, and stored in aliquots at $-80^{\circ} \mathrm{C}$ until enzyme analysis. Protein was measured with the BCA reagent according to the protocol of the supplier, using BSA as the standard.

Iodothyronine UGT activities were assayed usually by incubation of $1 \mu M \mathrm{~T} 4$ or T3 and $100,000 \mathrm{cpm}$ of the ${ }^{125} \mathrm{I}$-labeled compound for $60 \mathrm{~min}$ at $37^{\circ} \mathrm{C}$ with microsomes ( $1 \mathrm{mg}$ protein/mL) and $5 \mathrm{mMUDPGA}$ in $0.2 \mathrm{~mL} 75 \mathrm{mM}$ Tris/ $\mathrm{HCl}(\mathrm{pH} 7.8)$ and $7.5 \mathrm{mM} \mathrm{MgCl} 2$ in the presence of $0.025 \%$ (wt/vol) Brij 56 (Visser et al., 1993b). The reactions were stopped by addition of $0.2 \mathrm{~mL}$ ice-cold methanol, and after centrifugation, $200 \mu \mathrm{L}$ of the supernatants were mixed with $0.8 \mathrm{~mL} 0.1 \mathrm{M} \mathrm{HCl}$ and analyzed for glucuronide formation by chromatography on small Sephadex LH-20 columns (Visser et al., 1993b).

UGT activities for PNP, bilirubin, and androsterone were measured as previously described (Visser et al., 1993b). In short, assay mixtures for PNP UGT activity contained final concentrations of I $\mathrm{m} M$ PNP, $5 \mathrm{~m} M$ UDPGA, $0.25 \mathrm{mg}$ microsomal protein $/ \mathrm{mL}, 0.005 \%$ Brij $58,0.1 M$ Tris $/ \mathrm{HCl}$ (pH 7.4), and $5 \mathrm{mM} \mathrm{MgCl}$, and were incubated for 5 $15 \mathrm{~min}$ at $37^{\circ} \mathrm{C}$. Assay mixtures for bilirubin UGT activity contained $0.1 \mathrm{~m} M$ bilirubin, $0.125 \%$ BSA, $5 \mathrm{~m} M$ UDPGA,
$1 \mathrm{mg}$ microsomal protein $/ \mathrm{mL}, 0.025 \%$ Brij 56, 0.1 $M$ Tris/ $\mathrm{HCl}(\mathrm{pH} \mathrm{7.8)}$, and $3.75 \mathrm{mMMgCl}$, and were incubated for $15 \mathrm{~min}$ at $37^{\circ} \mathrm{C}$. Androsterone UGT assay mixtures contained $0.1 \mathrm{mM}$ androsterone, $\approx 50,000 \mathrm{dpm}\left[{ }^{3} \mathrm{H}\right]$ androsterone, $5 \mathrm{~m} M$ UDPGA, $0.5 \mathrm{mg}$ microsomal protein $/ \mathrm{mL}$, $0.005 \%$ Brij 56, 0.1 mM Tris/ $\mathrm{HCl}(\mathrm{pH} 7.4)$ and $3.75 \mathrm{mM}$ $\mathrm{MgCl}_{2}$, and were incubated for 15 min at $37^{\circ} \mathrm{C}$.

Type I iodothyronine deiodinase (ID-I) activity was determined essentially as previously described by incubation of I $\mu M$ rT3 and $\approx 100,000 \mathrm{cpm}\left[{ }^{125} \mathrm{I}\right] \mathrm{rT} 3$ for $30 \mathrm{~min}$ at $37^{\circ} \mathrm{C}$ with $10 \mu \mathrm{g}$ microsomal protein $/ \mathrm{mL}$ in $0.1 \mathrm{M}$ phosphate (pH 7.2), $2 \mathrm{~m} M$ EDTA, and $5 \mathrm{~m} M$ DTT (Visser et al., 1993b).

\section{Miscellaneous}

Serum T4 and T3 levels were determined by standard RIA procedures. Serum TSH was determined by RIA with the materials and protocols of the NIDDK, using TSH RP-2 as standard. Data are presented as mean \pm SD. The statistical significance of differences between groups of control and experimental animals was evaluated with Student's $t$-test. $P<0.05$ was considered significant

\section{Acknowledgment}

We thank Hans van Toor and Wout A. P. Breeman for expert experimental support.

\section{References}

Barter, R. A. and Klaassen, C. D. (1992a). Toxicol. Appl. Pharmacol. $113,36-42$

Barter, R. A. and Klaassen, C. D. (1992b). Toxicol. Appl. Pharmacol. $115,261-267$.

Beetstra, J. B., Van Engelen, J. G. M., Karels, P., Van der Hoek, H. J., De Jong, M., Docter, R., Krenning, E. P., Hennemann, G. Brouwer, A., and Visser, T. J. (1991). Endocrinology 128, $741-746$

Burchell, B., Coughtrie, M. W. H. and Jansen, P. L. M. (1994) Hepatology 20, 1622-1630.

Curran, P. G. and DeGroot, L. J. (1991). Endocr. Rev. 12, 135-150

Davies, P. H. and Franklyn, J. A. (1991). Eur. J. Clin. Pharmacol. 40, 439-451.

De Herder, W. W., Hazenberg, M. P.. Pennock-Schröder, A. M. Rutgers, M., and Visser, T. J. (1989). Life Sci. 45, 849-856.

De Sandro, V., Chevrier, M., Boddaert, A., Melcion, C., Cordier, A., and Richert, L. (1991). Toxicol. Appl. Pharmacol. 111,263-278.

De Sandro, V., Catinot, R., Kriszt, W., Cordier, A., and Richert, L. (1992). Biochem. Pharmacol 43, 1563-1569.

Emi, Y., Ikushiro, S. -I., and Iyanagi, T. (1995). J. Biochem. 117, 392-399.

Hazenberg, M. P., De Herder. W. W., and Visser, T. J. (1988). FEMS Microbiol. Rev. 54, 9-16.

Hegedüs, L., Hansen, J. M., Lühdorf, K., Perrild, H., FeldtRasmussen, U., and Kampmann, J.P. (1985). Clin. Endocrinol. 23, 423-429.

Homma, H., Kawai, H., Kubota, M., and Matsui, M. (1992). Biochim. Biophys. Acta 1138, 34-40.

Köhrle, J., Hesch, R. D., and Leonard, J. L. (1991). In: The thyroid Braverman, L. E. and Utiger, R. D. (eds.). Lippincott, Philadelphia, pp. 144-189. 
McClain, R. M. (1989). Toxicol. Pathol. 17, 294-306.

McClain, R. M., Levin, A. A., Posch, R., and Downing, J. C. (1989). Toxicol. Appl. Pharmacol. 99, 216-228.

Vguyen, T. T., DiStefano, J. J., Yamada, H., and Yen, Y. -M. (1993). Endocrinology 133, 2973-2983.

Owens, I. S. and Ritter, J. K. (1992). Pharmacogenetics 2, 93-108.

Qu, W., Kauffman, F.C., and Thurman. R. G. (1995).Arch. Biochem. Biophys. 319, 451-456.

Roy Chowdhury, J., Roy Chowdhury, N., Moscioni, A. D., Tukey, R., Tephley, T. R., and Arias, I. M. (1983). Biochim. Biophys. Acta $761,58-65$.

Rutgers, M., Heusdens, F. A., Bonthuis, F., De Herder, W. W., Hazenberg, M. P., and Visser. T. J. (1989). Endocrinology 125, $2822-2830$.

Saito, K.. Kaneko, H., Sato, K., Yoshitake, A., and Yamada, H. (1991). Toxicol. Appl. Pharmacol. 111, 99-106.

St. Germain, D. L. (1994). Trends Endocrinol. Metab. 5, 36-42.

Van der Heide, D., Schreurs, M., Van Snik. G., Schröder-van der Elst, J. P., Van der Bent, C., and Van Oosten, D. J. (1992). Throid 2(Suppl 2), S-62.
Van Raaij, J. A. G. M., Kaptein, E., Visser, T. J., and Van den Berg. K. J. (1993). Biochem. Pharmacol. 45, 627-631.

Van Steenbergen, W., Fevery, J.. De Vos, R., Leyten, R., Heirwegh. K. P. M., and De Groote, J. (1989). Hepatology 9, 314-321.

Visser, T. J. (1990). In: The thyroid gland. Greer, M. A. (ed.), Raven, New York, pp. 255-283.

Visser, T. J. (1994). In: Thyroid hormone metabolism; molecular biology and alternate pathways. $\mathrm{Wu}, \mathrm{S}-\mathrm{Y}$ and Visser, T. J. (eds.). CRC, Boca Raton, pp. 85-117.

Visser, T. J., Kaptein, E., and Harpur, E. S. (1991a). Biochem. Pharmacol. 42, 444446.

Visser, T. J., Gijzel, A., Kaptein, E., De Greef, W. J., and De Herder, W. W. (1991b). Ann. Endocrinol. 52, 72.

Visser, T. J., Kaptein, E., Van Raaij, J. A. G. M., Tjong Tjin Joe, C.. Ebner, T., and Burchell, B. (1993a). FEBS Lett. 315, 65-68.

Visser, T. J., Kaptein, E., Van Toor, H., Van Raaij. J. A. G. M., Van den Berg. K. J., Tjong Tjin Joe, C., Van Engelen, J. G. M., and Brouwer, A. (1993b). Endocrinology 133, 2177-2186.

Visser, T. J., Kaptein, E., Gijzel, A. L., De Herder, W. W., Ebner, T. and Burchell, B. (1993). FEBS Lett. 324, 358-360. 